\title{
Technical Note: On the Production and Accuracy of CNC-Manufactured Hydraulic Scale Models
}

\author{
Jochen Aberle ${ }^{1, * \mathbb{C}}$, Ralph Eikenberg ${ }^{1}$, Till Branß ${ }^{1} \mathbb{( D}$ and Pierre-Yves Henry ${ }^{2} \mathbb{C}$ \\ 1 Division of Hydraulic Engineering and River Morphology, Leichtweiß Institute for Hydraulic Engineering \\ and Water Resources, Technische Universität Braunschweig, Beethovenstr. 51a, \\ 38106 Braunschweig, Germany; r.eikenberg@tu-braunschweig.de (R.E.); t.branss@tu-braunschweig.de (T.B.) \\ 2 Department Ships and Ocean Structures, SINTEF Ocean, Otto Nielsens vei 10, 7052 Trondheim, Norway; \\ pierreyves.henry@sintef.no \\ * Correspondence: jochen.aberle@tu-braunschweig.de; Tel.: +49-531-3913940
}

Citation: Aberle, J.; Eikenberg, R.;

Branß, T.; Henry, P.-Y. Technical Note: On the Production and Accuracy of CNC-Manufactured Hydraulic Scale Models. Water 2021, 13, 916.

https://doi.org/10.3390/w13070916

Academic Editor: Manousos

Valyrakis

Received: 3 March 2021

Accepted: 25 March 2021

Published: 27 March 2021

Publisher's Note: MDPI stays neutral with regard to jurisdictional claims in published maps and institutional affiliations.

Copyright: (c) 2021 by the authors. Licensee MDPI, Basel, Switzerland. This article is an open access article distributed under the terms and conditions of the Creative Commons Attribution (CC BY) license (https:/ / creativecommons.org/licenses/by/ $4.0 /)$.

\begin{abstract}
This Technical Note addresses the workflow for the production of hydraulic scale models using a Computer Numerically Controlled (CNC) production technique and investigates the possibilities to accurately reproduce topographical roughness features. Focusing on the construction of three scale models of unlined rock blasted tunnels, their accuracy is evaluated based on the comparison of differences between scaled prototype point clouds obtained by terrestrial laser scanning, spatially filtered meshes that served as input for the milling of the models, and digital twins of the constructed models that were created by Structure from Motion photogrammetry. The direct comparison between the point clouds and meshes as well as the comparison of derived statistical parameters show that the models could be reproduced with a high degree of accuracy. Observed deviations between the point clouds of the milled models and the milling meshes, as well as the scaled original point cloud, are identified and discussed in light of the production technique and the accuracy of the applied methods for the comparison.
\end{abstract}

Keywords: accuracy; hydropower; rock-blasted tunnel; scale model; Structure from Motion; roughness

\section{Introduction}

Hydraulic physical modelling offers a practical and economical way to develop a better understanding of hydraulic processes and to solve complex hydraulic problems. Physical scale models have a long tradition and are an established technique to design and test hydraulic structures, to solve problems in river and coastal applications, and to provide data for the validation of numerical models as well as for the derivation of novel theories and approaches [1-7]. This is reflected by a vast body of scientific and grey literature on the design of physical scale models, similitude criteria, and scale effects [1-9].

Recent developments in digital technology have offered new opportunities to design and conduct experimental studies [1,5]. One example, which is in the focus of this technical note, is the accurate representation of prototype bathymetry and roughness features in fixed bed surface models. Traditionally, surface models have been constructed manually by forming a skeleton of the model body using arbitrarily spaced cross-sectional profiles. The model elevations at the profiles match the scaled elevations of the prototype surface, but topographic details between the profiles, as well as particular roughness characteristics, may not be correctly reproduced. In order to achieve similarity of bulk hydraulic characteristics between the model and the prototype, such models are typically calibrated by adjusting the model surface roughness, for example, by smoothing or roughening the surface with additional material such as sand or flexible strips $[9,10]$. However, differences in the roughness pattern between the model and prototype may result in differences in the near bed turbulent flow patterns and boundary layer characteristics, which may result in both scale and laboratory effects and, hence, uncertainties $[1-4,11]$. 
Casting and Computer Numerically Controlled (CNC) manufacturing techniques can be used to achieve a high similitude between prototype and model surfaces [10]. Casting methods represent a rather classical technique for reproducing surface features by filling a mould with liquified material which is then allowed to harden. Casting has been used, for example, to reproduce gravel bed surfaces and to investigate the influence of bed porosity on flow characteristics [12-18]. Despite the high accuracy that may be achieved by this technique, it has shortcomings, as the original surface may be destroyed or altered when creating the mould, and because the mould cannot be easily scaled down.

CNC-manufacturing methods such as 3D-printing or milling represent a digital technique to reproduce surfaces. These methods require Digital Elevation Models (DEMs) as an input that can be obtained by common remote sensing techniques such as terrestrial laser scanning (TLS), sonar surveys or photogrammetric methods [19-21]. Although both techniques are limited to the spatial scale of the CNC-machine, it is possible to construct models of a larger spatial extent by producing tiles or sections that can be assembled to form the final model. Care needs to be taken to avoid buoyancy effects, if the density of the material used for model production is lower than that of water [10]. Moreover, it is possible to scale the DEM with a desired scale factor before manufacturing the model, and CNC-manufacturing methods can also be used to produce scaled moulds [22,23].

Additive manufacturing, or 3D-printing, typically starts from a flat horizontal surface, and the model body is created by applying successive layers of a liquid material through a small feeding conduct placed on a CNC-robot arm. The material used for additive manufacturing needs to harden relatively fast so that the next layer can be applied. Many different materials can be used for additive manufacturing, which becomes apparent from the different disciplines making use of this technique such as medicine, biomimetics, oceanography, microfluidics, construction, etc. [24-29]. It can therefore be expected that additive manufacturing, which has already been successfully used in hydraulic studies [30,31], will have a significant impact on the construction of scale models in the future, especially regarding hydraulic structures.

Constructing a model by 3D-milling means that it is progressively shaped from a solid block of material using a CNC-controlled robot arm together with differently sized milling heads. The blocks used for the milling can consist of different materials such as foams and metal alloys, and the accuracy of the milled surface or object depends on the accuracy of the DEM as well as the size of the milling head [10]. The milling technique is used in various hydraulic laboratories for the construction of scale models and has already been successfully applied to construct artificial self-affine rough beds, scaled versions of rough waterways, conduits, and hydraulic structures $[10,22,23,32-34]$. The accuracy of milled models is directly visible by eye, but has seldomly been quantified. For example, Henry et al. [10] investigated the accuracy of a part of a 1:15 scale model of an unlined rock blasted tunnel which was scanned by terrestrial laser scanning. The comparison of the obtained point cloud with the topography extracted from the DEM that served as input for the milling, revealed that $94.6 \%$ of the scanned points were less than $3 \mathrm{~mm}$ away from the scaled DEM and that $71 \%$ of the points were in a distance of $\pm 1.5 \mathrm{~mm}$ from the scaled DEM. These results showed that a high accuracy could be achieved and the deviations were attributed to the size of the milling heads.

In this technical note (TN), we expand and complement the results presented by Henry et al. [10] in regard to the topographical accuracy of milled scale models by novel data from three milled scale models of unlined rock-blasted tunnels. Using digital twins of the milled scale models, which were created by Structure from Motion photogrammetry (SfM), the accuracy of the tunnel models is assessed at different production stages. We note that the focus of the TN is on the milling of the tunnel models. Information on the experimental setup and procedure as well as the results from the scale model tests are reported in further publications [34,35]. The technical note is structured as follows: Section 2 presents the available data and the workflow to construct the models, Section 3 contains the description of the results, and the discussion in Section 4 concludes the technical note. 


\section{Material and Methods}

TLS-scans of unlined rock-blasted tunnel sections belonging to the Evanger hydroelectric power station in Norway served as the input for the construction of the three scale-models. The TLS-data were acquired during a maintenance period of the hydropower station with a Leica P40 Laserscanner, a time-of-flight scanner with a 3D positional accuracy of $3 \mathrm{~mm}$ at $50-\mathrm{m}$ distance, a beam divergence of $<0.23 \mathrm{mrad}$ and a beam size of $\leq 3.5 \mathrm{~mm}$ at front window. The instrument was positioned approximately every $15 \mathrm{~m}$ for the scanning of a $4 \mathrm{~km}$ and $2.6 \mathrm{~km}$ long tunnel reach, respectively. The scanning positions were registered using a Leica Nova TS50 total station (pinpoint edm-accuracy of $0.6 \mathrm{~mm}+2 \mathrm{ppm}$ and angular accuracy of $0.15 \mathrm{mgon})$, and the scan data were processed within the Leica Cyclone environment to merge the overlapping point clouds. We note that the tunnel invert could not be completely drained of water for the scan, so that parts of the tunnel invert could not be accurately scanned. However, compared to the rough tunnel walls, the tunnel invert was reasonably smooth, so that the missing data could be easily interpolated.

The scale-model tests were designed to investigate the effect of the wall rock roughness on head losses and the friction factor in the tunnels [34,35]. It was therefore decided to construct models of rather straight tunnel sections to avoid the additional influence of bends, alcoves, and partial linings. A geometrical scale of 1:15 was chosen and the length of the tunnel models was restricted to a length of $11.90 \mathrm{~m}$ (178.5 $\mathrm{m}$ in prototype conditions). Figure 1 shows the planform of the tunnel reaches that were used for the scale-model construction and defines the names of the three tunnel-models that will be used in the following. Note that the names indicate the spatial areas where the scans were carried out.

\section{Bjørndal 1}

\section{Bjørndal 2}

\section{Grøndal}

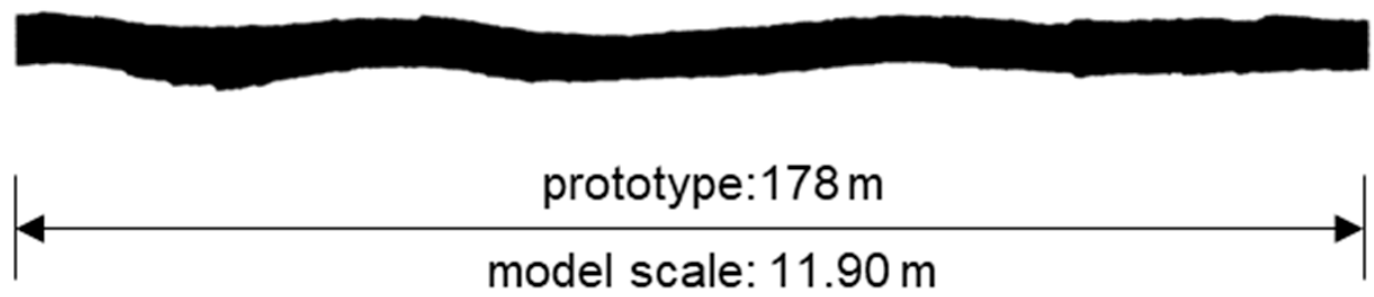

Figure 1. Planform of the tunnel-models Bjørndal 1, Bjørndal 2, and Grøndal.

The workflow for producing the scale models is depicted in Figure 2. The required steps for the production of the scale models included the post-processing of the TLSdata, the milling and the post-processing of the milled tunnel parts. These steps were complemented by the generation of digital twins of the milled model parts for the evaluation of the spatial accuracy before the final assemblage of the tunnels for the subsequent hydraulic experiments. 


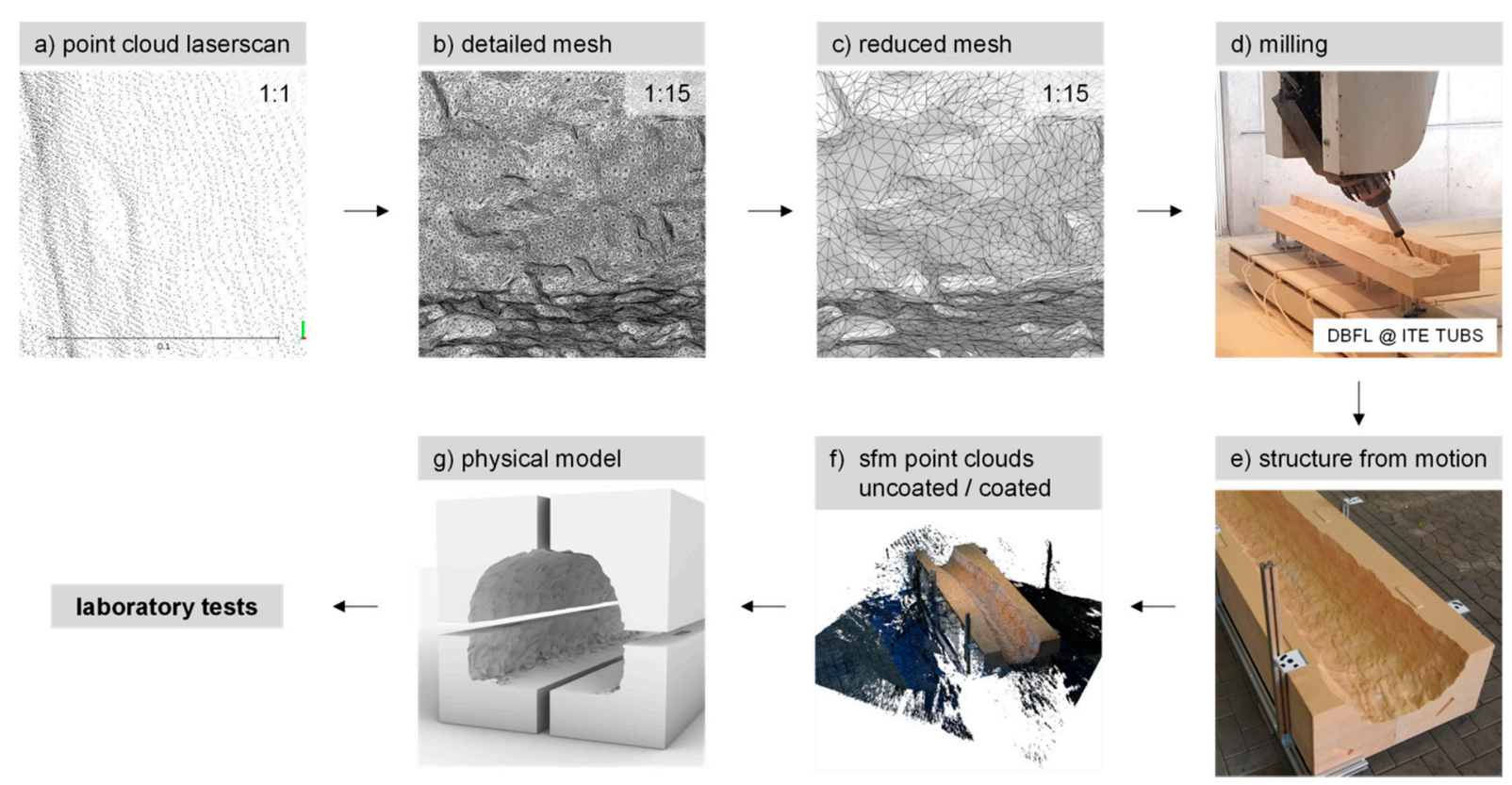

Figure 2. Workflow for the production of 1:15 scale models of unlined rock blasted hydropower tunnels and the subsequent assessment of the accuracy of the milled tunnel parts. (a) point cloud section of the laserscan in prototype scale, (b) visualization of a part of the detailed scaled mesh, (c) visualization of the reduced mesh of the same location as in (b), (d) photograph taken during the milling of a segment, (e) setup of two combined segments for structure from motion, (f) point cloud created by structure from motion for coated/uncoated segments, (g) sketch visualizing the final assembly of a tunnel section from the milled segments.

The TLS point clouds of the model sections had a high spatial resolution in prototype dimension which becomes apparent from the number of points (approximately 335 Mio., 386 Mio., and 282 Mio. data points and average point densities of 66,817, 88,191, and 97,459 points $/ \mathrm{m}^{2}$ for Bjørndal 1, Bjørndal 2, and Grøndal, respectively). In order to guarantee the manageability of the data for the milling, it was necessary to reduce the spatial resolution. This was done by downscaling the point clouds by the geometrical scale factor of 1:15 and generating triangulated meshes using the 3DReshaper 2017 MR1 (17.1) software package from Leica Geosystems. This strategy reduced the number of data points to a total number of approx. 5.3 million vertices (approx. 10 million faces) per tunnel-model. The created meshes were still too detailed to be processed by the milling machine software, so that they were further reduced to approx. 900,000 faces per tunnel using the open-source software MeshLab (version 20190129-beta). This corresponded to a further reduction of faces of about $90 \%$ compared to the detailed meshes (Figure $2 b, c$ ) by which the surface curvature was sustained as much as possible. The reduced meshes were then used for creating the required input files for the milling at the Digital Building Fabrication Laboratory (DBFL) at TU Braunschweig [36].

The milling of the tunnel-models followed the strategy described in other studies [10,34]. The total length of the tunnel models exceeded both the spatial scale of the 5-axis CNCcontrolled milling facility at the DBFL and the spatial dimensions of the base material used for milling, so that each tunnel-model was subdivided in five tunnel segments. Moreover, a tunnel is a closed conduit and each tunnel section was therefore additionally divided in four segments (Figure $2 \mathrm{~g}$ ) to be able to mill out edges and cavities.

The base material used for the milling consisted of 2440-mm long, 1220-mm wide, and 92-mm high plates out of Divinycell H60, a low-density polyvinylchloride (PVC) foam material. The long side of the plates determined the length of a tunnel section and the plates were glued together using RenCast ${ }^{\circledR} \mathrm{FC} 52$, a fast hardening casting resin, to form blocks of the required height for the milling (Figure 2d). The dimensions of the individual tunnel segments determined the required number of plates. Care was taken to obtain 
a wall thickness that could withstand the pressure in the subsequent laboratory tests. For gluing, the plates were fixed on a stiff horizontal plate to avoid warping during the curing process.

Each segment was milled in four steps. First, the raw blocks were machined by a roller cutter (80-mm diameter) to produce flat surfaces on the outside surfaces of the blocks. This was done to aid with the gluing of the tunnel segments and sections when constructing the final model. Second, key and slot joints were milled by an $8 \mathrm{~mm}$ shaft tool to aid with the merging of the segments and sections (cf. Figure 2e). Third, a shaft tool (40 $\mathrm{mm}$ ) was used for rough milling of the tunnel surface to save time for the fourth step, the fine milling. For the latter, the tunnel surface was milled by a ball nose cutter with a diameter of $12 \mathrm{~mm}$ and a web spacing of $2 \mathrm{~mm}$.

The surface structure of the milled parts had fine protruding fringes due to the operation principle of the ball nose cutter, which were manually removed by brushing the milled surfaces. In order to reinforce the surface and to improve the water tightness, a polyester coating $\left(\operatorname{RenLam}{ }^{\circledR}\right)$ was manually applied on the milled surfaces before the segments were glued together. The required milling time for each tunnel model was approximately $100 \mathrm{~h}$ including rigging and handling.

The described workflow includes digital and physical steps which may be associated with a loss of accuracy. These are the reduction of the spatial resolution, the milling, and the surface coating. For the assessment of the achieved accuracy, digital twins of the milled tunnels were created by SfM before and after surface coating (Figure 2e,f). For this purpose, the segments were fixed to a special frame rack on which reference markers were placed (0.5-1 $\mathrm{mm}$ accuracy). Photographs were taken from different angles by digital reflex cameras (Nikon D7200, lens AF-S DX NIKKOR 18-140 mm 1:3.5-5.6 G ED VR; Nikon D5100, lens AF-S DX NIKKOR 18-55 mm 1:3.5-5.6 G ED II). Care was taken to have enough photos with a high depth of focus, high overlap, and good exposure conditions without reflections. The photographs were processed with the SfM software AgiSoft Photoscan Professional (version 1.4.1, 64 bit).

We note that we used slightly different strategies for SfM, as we created both point clouds of individual segments (Bjørndal 1, Bjørndal 2 without coating) as well as of two combined segments forming the bottom and wall parts of the tunnels, respectively (Bjørndal 2 with coating and Grøndal; cf. Figure 2e). The latter strategy was followed to optimize the workflow in order to save time for the post-processing. We further note that no data were available for the uncoated Grøndal segments and for one segment of the uncoated Bjørndal 1 model due to technical problems that resulted in the loss of the digital photographs.

The resulting point clouds of the milled model parts were further post-processed by the open-source software CloudCompare (v2.11.3 anoia and v2.12 alpha). Postprocessing consisted of roughly cropping the single point clouds to the area of the tunnel surface and aligning them via the Iterative Closest Point (ICP) algorithm in CloudCompare [37] to the corresponding parts of the milling mesh. This was done in order to remove all points and cloud artefacts that were more than a certain distance away from the milling mesh by using an iteratively adapted distance of 7-20 mm, depending on the individual cloud. Each surface part was aligned again with the corresponding mesh part by the ICP algorithm. Finally, the individual point clouds were merged to form the entire tunnel model representing the digital twin of the milled model. The key data of the point clouds are summarized in Table 1 together with information on the TLS data. 
Table 1. Summary of point cloud and mesh characteristics for each tunnel model. All dimensions are in model scale (1:15), except for the prototype point-cloud.

\begin{tabular}{|c|c|c|c|c|c|}
\hline & Steps & $\begin{array}{l}\text { Total Length } \\
\text { (m) }\end{array}$ & $\begin{array}{c}\text { Total Points } \\
\text { (-) }\end{array}$ & $\begin{array}{l}\text { Total Surface Area } \\
\qquad\left(\mathrm{m}^{2}\right)\end{array}$ & $\begin{array}{l}\text { Point Density } \\
\left(\mathrm{pts} / \mathrm{m}^{2}\right)\end{array}$ \\
\hline \multirow{4}{*}{ Bjørndal 1} & Prototype point cloud ${ }^{(2)}$ & 178.50 & $344,817,314$ & 4,001 & 86,191 \\
\hline & Milling mesh & 11.90 & 684,515 & 17.78 & 38,498 \\
\hline & SfM point cloud uncoated $(3)$ & 9.52 & $97,791,710$ & 14.21 & $6,880,408$ \\
\hline & SfM point cloud coated & $11.91^{(4)}$ & $82,556,506$ & 17.78 & $4,643,094$ \\
\hline \multirow{4}{*}{ Bjørndal 2} & Prototype point cloud ${ }^{(2)}$ & 178.36 & $386,099,896$ & 3,962 & 97,459 \\
\hline & Milling mesh & 11.90 & 703,182 & 17.61 & 39,937 \\
\hline & SfM point cloud uncoated & 11.90 & $251,039,847$ & 17.61 & $14,257,657$ \\
\hline & SfM point cloud coated & 11.91 & $78,743,193$ & 17.61 & $4,472,172$ \\
\hline \multirow{4}{*}{ Grøndal } & Prototype point cloud ${ }^{(2)}$ & 178.56 & $282,057,286$ & 4,221 & 66,816 \\
\hline & Milling mesh & $11.89^{(5)}$ & 719,253 & 18.76 & 38,336 \\
\hline & SfM point cloud uncoated & (1) & (1) & (1) & (1) \\
\hline & SfM point cloud coated & 11.89 & $45,075,401$ & 18.76 & $2,402,538$ \\
\hline
\end{tabular}

${ }^{(1)}$ no data available for the uncoated model; ${ }^{(2)}$ the prototype point clouds were cut manually for the comparison resulting in a length $>178 \mathrm{~m}$; however, only overlapping parts were used for the comparison; ${ }^{(3)}$ the data of the last tunnel segment was corrupted and could not be further analyzed; ${ }^{(4)}$ this point cloud was created by aligning the individual point clouds with the mesh resulting in a small deviation; (5) the last segment was $0.01 \mathrm{~m}$ shorter than the others.

\section{Results}

\subsection{Comparison of Point Clouds and Meshes}

The accuracy of the physical models was assessed by comparing (1) the scaled prototype point clouds with the milling meshes; (2) the milling meshes with the digital twins of the uncoated and coated models, respectively; (3) the scaled prototype point clouds with the digital twins of the coated models; and (4) the digital twins of the uncoated models with the ones of the coated models. For the comparison, the respective point clouds and meshes were aligned using the ICP algorithm by minimizing the square errors between correspondences between the reference point cloud and the point cloud used for the comparison [38]. The distribution of the distances between the reference and target data were evaluated in Matlab (version 2020a) based on .PLY files (Polygon File Format) exported from CloudCompare. Table 2 summarizes the mean deviations, standard deviations, and the 5th and 95th percentiles of the distribution of the distances. Particularly, the low mean and standard deviations for the different comparisons show that the point clouds could be overlapped with a high degree of accuracy.

The interval between the 5th and 95th percentile defines the range in which $90 \%$ of the distances fall. This $90 \%$ range corresponded to max. $3.6 \mathrm{~mm}$ for the comparison of the milling meshes with the point clouds of the uncoated models. We note that researchers [10] reported similar results for the comparison of the milling mesh and a TLS point cloud of a milled wall segment. The comparison of the milling meshes with the point clouds of the coated models resulted in a max. $90 \%$ range of $4.4 \mathrm{~mm}$. This indicates that the applied coating resulted generally in a slightly increased difference of approximately $0.8 \mathrm{~mm}$. The direct comparison of the point clouds of the uncoated and coated models showed a $90 \%$ range of $1 \mathrm{~mm}$ and $2.7 \mathrm{~mm}$ for Bjørndal 1 and Bjørndal 2, respectively.

The comparison of the scaled prototype point cloud with the milling mesh showed that the reduction of the spatial resolution and the triangulation resulted in similar differences as those obtained for the comparison of the milling mesh with coated and uncoated point clouds. The largest differences were observed for the comparison of the scaled prototype point clouds with the point clouds of the coated models, for which the $90 \%$ ranges corresponded to $24 \mathrm{~mm}, 28 \mathrm{~mm}$, and $17 \mathrm{~mm}$ for Bjørndal 1, Bjørndal 2, and Grøndal, respectively. These values, however, should be seen in light of the reduction of the spatial scales, the uncertainties associated with SfM, point cloud registration, and the combination of the point clouds. Overall, the results presented above show that the models 
could be reproduced with a high degree of accuracy and that the coating did not alter the surface significantly.

Table 2. Summary of mean deviations, standard deviations, and the 5 th and 95 th percentile from the comparison between the point clouds and meshes. All dimensions are provided in model scale. The asterisks denote the reference point cloud for the comparison.

\begin{tabular}{|c|c|c|c|c|}
\hline Comparison of & & Bjørndal 1 & Bjørndal 2 & Grøndal \\
\hline \multirow{4}{*}{$\begin{array}{l}\text { Scaled prototype point } \\
\text { cloud * and } \\
\text { milling mesh }\end{array}$} & mean deviation (m) & $7.5 \times 10^{-4}$ & $9.3 \times 10^{-4}$ & $7.9 \times 10^{-4}$ \\
\hline & standard deviation $(\mathrm{m})$ & $6.9 \times 10^{-4}$ & $8.8 \times 10^{-4}$ & $7.7 \times 10^{-4}$ \\
\hline & 5 th percentile $(\mathrm{m})$ & $1.1 \times 10^{-4}$ & $1.7 \times 10^{-4}$ & $1.2 \times 10^{-4}$ \\
\hline & 95th percentile $(\mathrm{m})$ & $2.1 \times 10^{-3}$ & $2.3 \times 10^{-3}$ & $2.1 \times 10^{-3}$ \\
\hline \multirow{4}{*}{$\begin{array}{l}\text { Milling mesh * and SfM } \\
\text { point cloud uncoated }\end{array}$} & mean deviation (m) & $1.6 \times 10^{-4}$ & $-3.4 \times 10^{-5}$ & $\mathrm{~N} / \mathrm{A}$ \\
\hline & standard deviation $(\mathrm{m})$ & $2.0 \times 10^{-3}$ & $1.2 \times 10^{-3}$ & $\mathrm{~N} / \mathrm{A}$ \\
\hline & 5th percentile $(\mathrm{m})$ & $1.6 \times 10^{-3}$ & $-1.8 \times 10^{-3}$ & $\mathrm{~N} / \mathrm{A}$ \\
\hline & 95th percentile (m) & $2.0 \times 10^{-3}$ & $1.6 \times 10^{-3}$ & $\mathrm{~N} / \mathrm{A}$ \\
\hline \multirow{4}{*}{$\begin{array}{l}\text { Milling mesh * and SfM } \\
\text { point cloud coated }\end{array}$} & mean deviation (m) & $-5.4 \times 10^{-6}$ & $-9.7 \times 10^{-5}$ & $1.1 \times 10^{-4}$ \\
\hline & standard deviation (m) & $1.2 \times 10^{-3}$ & $1.5 \times 10^{-3}$ & $1.4 \times 10^{-3}$ \\
\hline & 5 th percentile $(\mathrm{m})$ & $-1.7 \times 10^{-3}$ & $-2.4 \times 10^{-3}$ & $-2.1 \times 10^{-3}$ \\
\hline & 95th percentile $(\mathrm{m})$ & $1.7 \times 10^{-3}$ & $1.9 \times 10^{-3}$ & $2.3 \times 10^{-3}$ \\
\hline \multirow{4}{*}{$\begin{array}{l}\text { Scaled prototype point } \\
\text { cloud * and SfM point } \\
\text { cloud coated }\end{array}$} & mean deviation (m) & $4.2 \times 10^{-3}$ & $5.3 \times 10^{-3}$ & $3.5 \times 10^{-3}$ \\
\hline & standard deviation (m) & $9.9 \times 10^{-3}$ & $1.2 \times 10^{-2}$ & $9.6 \times 10^{-3}$ \\
\hline & 5 th percentile $(\mathrm{m})$ & $1.6 \times 10^{-4}$ & $1.8 \times 10^{-4}$ & $1.7 \times 10^{-4}$ \\
\hline & 95th percentile $(\mathrm{m})$ & $2.5 \times 10^{-2}$ & $2.8 \times 10^{-2}$ & $1.7 \times 10^{-2}$ \\
\hline \multirow{4}{*}{$\begin{array}{l}\text { SfM point cloud } \\
\text { uncoated }{ }^{*} \text { and SfM } \\
\text { point cloud coated }\end{array}$} & mean deviation (m) & $4.8 \times 10^{-4}$ & $9.6 \times 10^{-4}$ & $\mathrm{~N} / \mathrm{A}$ \\
\hline & standard deviation $(\mathrm{m})$ & $4.4 \times 10^{-4}$ & $1.0 \times 10^{-3}$ & $\mathrm{~N} / \mathrm{A}$ \\
\hline & 5th percentile $(\mathrm{m})$ & $1.3 \times 10^{-4}$ & $1.3 \times 10^{-4}$ & $\mathrm{~N} / \mathrm{A}$ \\
\hline & 95th percentile $(\mathrm{m})$ & $1.2 \times 10^{-3}$ & $2.8 \times 10^{-3}$ & $\mathrm{~N} / \mathrm{A}$ \\
\hline
\end{tabular}

\subsection{Accuracy Assessment Based on Statistical Parameters}

In a further step, we determined statistical parameters of the rough tunnel surfaces for an additional assessment of the model accuracy. For this purpose, the meshes and point clouds were transformed into a structured grid in cylindrical coordinates (CDEM) for which the longitudinal coordinate served as reference direction for the main axis. The CDEMs were composed of 2300 equally spaced tunnel cross-sections $(\Delta x=0.0052 \mathrm{~m})$ each consisting of 300 points along the perimeter of the horseshoe shaped cross-sectional area (i.e., by using 300 different angular coordinates; $\Delta \varphi=1.2^{\circ}$ ). We note that one fifth of the cross-sections belonging to the last tunnel segment of the uncoated Bjørndal 1 model could not be used due to the aforementioned corrupted files, which is also the reason for the reduced length of the uncoated SfM point cloud of this tunnel in Table 1. The CDEMs were used to extract wall-profiles along the $x$-axis for constant angular coordinates $\varphi$ that characterized the rough tunnel walls, i.e., profiles characterizing the rather smooth tunnel invert were discarded in the analysis. Each profile was linearly detrended and the standard deviation $\sigma$, skewness Sk, and kurtosis Ku were determined. The corresponding mean values of the analyzed profiles are reported in Table 3 for each available tunnel model and production stage. We further used the CDEMs to assess the mean cross-sectional areas $\mathrm{A}$, the mean maximum tunnel width $\mathrm{W}$, and the mean maximum tunnel height $\mathrm{H}$ (Table 3). The latter values were determined by averaging the maximum distances between the left and right tunnel wall, and between the tunnel invert and roof for all analyzed tunnel cross-sections, respectively. 
Table 3. Mean standard deviation $\sigma$, skewness, and kurtosis of the CDEM profile-analyses, the mean cross-sectional area, and the mean wetted perimeter.

\begin{tabular}{cccccccc}
\hline Tunnel & CDEM & $\boldsymbol{\sigma}(\mathbf{m})$ & $\mathbf{S k}$ & $\mathbf{K u}$ & $\mathbf{A}\left(\mathbf{m}^{2}\right)$ & $\mathbf{W}(\mathbf{m})$ & $\mathbf{H}(\mathbf{m})$ \\
\hline \multirow{4}{*}{ Bjørndal 1 } & Scaled prototype & $7.92 \times 10^{-3}$ & $1.11 \times 10^{-1}$ & 3.06 & 0.1406 & 0.463 & 0.369 \\
& Milling mesh & $8.30 \times 10^{-3}$ & $8.60 \times 10^{-3}$ & 3.09 & 0.1405 & 0.460 & 0.368 \\
& Uncoated & $8.10 \times 10^{-3}$ & $-8.93 \times 10^{-2}$ & 3.22 & 0.1403 & 0.460 & 0.368 \\
& Coated & $8.20 \times 10^{-3}$ & $2.86 \times 10^{-2}$ & 3.15 & 0.1405 & 0.461 & 0.369 \\
\hline \multirow{3}{*}{ Bjørndal 2 } & Scaled prototype & $1.73 \times 10^{-2}$ & $-1.09 \times 10^{-1}$ & 2.55 & 0.1338 & 0.459 & 0.346 \\
& Milling mesh & $1.88 \times 10^{-2}$ & $-1.50 \times 10^{-1}$ & 2.33 & 0.1337 & 0.458 & 0.345 \\
& Uncoated & $1.89 \times 10^{-2}$ & $-1.16 \times 10^{-1}$ & 2.45 & 0.1334 & 0.458 & 0.346 \\
& Coated & $1.86 \times 10^{-2}$ & $-1.62 \times 10^{-1}$ & 2.34 & 0.1332 & 0.458 & 0.345 \\
\hline \multirow{2}{*}{ Grøndal } & Scaled prototype & $4.56 \times 10^{-2}$ & $-3.65 \times 10^{-1}$ & 2.80 & 0.1458 & 0.440 & 0.408 \\
& Milling mesh & $4.61 \times 10^{-2}$ & $-3.64 \times 10^{-1}$ & 2.79 & 0.1455 & 0.440 & 0.406 \\
& Coated & $4.57 \times 10^{-2}$ & $-3.25 \times 10^{-1}$ & 2.83 & 0.1442 & 0.437 & 0.406 \\
\hline
\end{tabular}

The differences between the mean standard deviations of the milling mesh CDEMs and the CDEMs of the coated and uncoated models, respectively, are smaller than $0.4 \mathrm{~mm}$ for each tunnel. This difference is in the order of magnitude of the measurement accuracy and confirms the findings from the point cloud-mesh comparisons that the model topography was reproduced with high accuracy. This is further supported by the similar mean skewness and mean kurtosis values for each tunnel. Slightly larger deviations can be observed for the comparison of the statistical parameters from the scaled prototype CDEMS with the milling mesh CDEMs and the coated and uncoated CDEMs, respectively. However, these differences are smaller than $1.6 \mathrm{~mm}$ and indicate a good agreement. This, in turn, is an indicator that the aforementioned larger deviations between the scaled prototype cloud and the point clouds of the milled models are reasonable, especially when considering the intermediate working steps to construct the models and the methodological uncertainties. This conclusion can be further justified by the comparison of the mean cross-sectional areas for each tunnel, which shows only minor differences (the maximum deviation was observed for Grøndal and corresponded to $0.0016 \mathrm{~m}^{2}$ ). The comparison of the mean maximum width and height resulted also in negligible differences which were smaller than $0.003 \mathrm{~m}$.

The final step of our assessment was the comparison of the single sided spectra of the CDEM-profiles, which is shown in Figure 3. This comparison reveals no major differences in the spectra for wavelengths larger than $0.05 \mathrm{~m}$ (note that the peaks shown in the spectra reflect the tunnel blasting frequency). The separation of the power spectra for smaller wavelengths can be explained by the reduction of the spatial resolution and the manufacturing of the tunnel models. The reduction in spatial resolution corresponds basically to a low pass filter, so that the spectra for the milling mesh CDEM falls below the spectra of the scaled prototype CDEM at small wavelengths. The milled surfaces, that were produced on the basis of the milling mesh, are rougher than the milling mesh at small wavelengths due to surface properties of the material as well as the milling procedure, so that these spectra fall in the intermediate region between the spectra of the milling CDEM and the scaled prototype CDEMs. To summarize, the spectra further confirm the high degree of accuracy that could be achieved by the CNC-based milling approach. 
a)

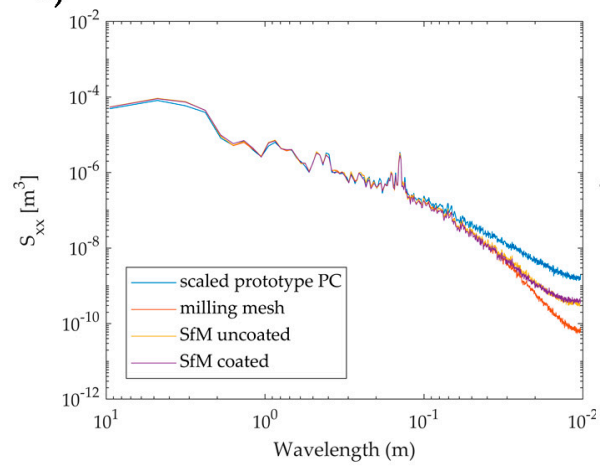

b)

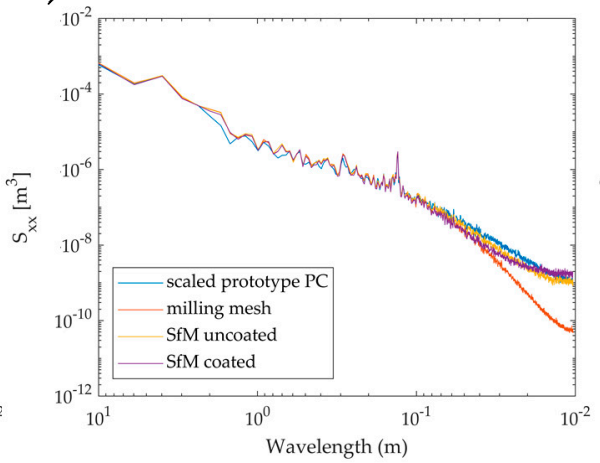

c)

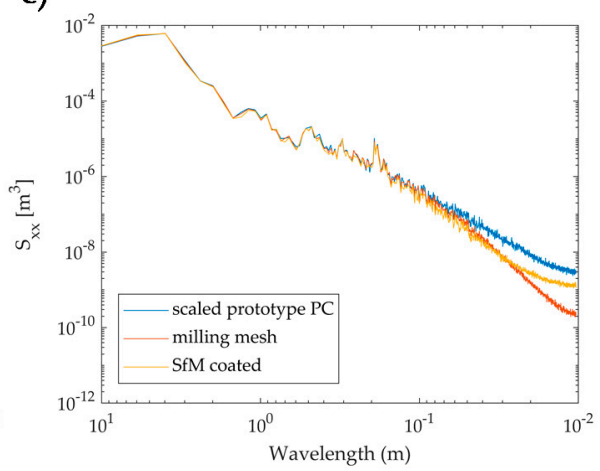

Figure 3. Comparison of the single sided power spectra of the available CDEMs for (a) Bjørndal 1, (b) Bjørndal 2, and (c) Grøndal.

\section{Discussion}

The results from the comparative analyses showed that the tunnel topography could be reproduced with a high degree of accuracy. The differences between the scaled prototype point clouds and the milling meshes were small and result from the reduction of the spatial resolution. Consequently, large scale features could be reproduced with a high degree of accuracy, which becomes apparent from the spectra shown in Figure 3.

The comparison of the milling meshes with the point clouds of the uncoated and coated models, respectively, revealed a high degree of reproducibility, although both the direct comparison of the point clouds and meshes (Table 2), the comparison of statistical parameters derived from the CDEMs (Table 3), and the spectra (Figure 3) indicated minor differences. The reason for these differences can be manifold, as they may be related to the accuracy of the applied methods for surveying the milled tunnel models (SfM and generation of digital twins), the methods used for the comparison (ICP etc.), and to physical differences of the models resulting from the milling. The first two issues were already highlighted in Section 3 and this discussion will not be repeated here in detail. Instead, it is worth considering the last issue regarding the milling in some more detail.

As stated by other Henry et al. [10], the size of the finest milling head is the main parameter controlling the accuracy and the amount of "smoothing" involved in the milling process. In our case, the loss of accuracy was determined by the $12-\mathrm{mm}$ ball nose cutter and the web spacing of $2 \mathrm{~mm}$. Moreover, compared to other authors [10], we investigated the accuracy of the total tunnels and not only of one segment, so that the uncertainties arising from the contact surfaces between the individual segments and sections must also be considered. This is exemplarily shown in Figure 4a visualizing the difference plot between the milling mesh and the SfM point cloud of the coated Bjørndal 2 model. The overall light green colour indicates the good agreement between the mesh and the point cloud, but slightly larger differences can generally be identified at the contact surfaces between the individual segments and sections, respectively. We note that the shown differences are associated with the digital twin of the physical model and that they result from the digital alignment procedure of the tunnel segments and sections. However, differences associated with the contact surfaces could also be identified by the visual inspection of the physical models so that we hypothesize that the observed differences can be used to characterize also the accuracy of the physical model. 
(a)

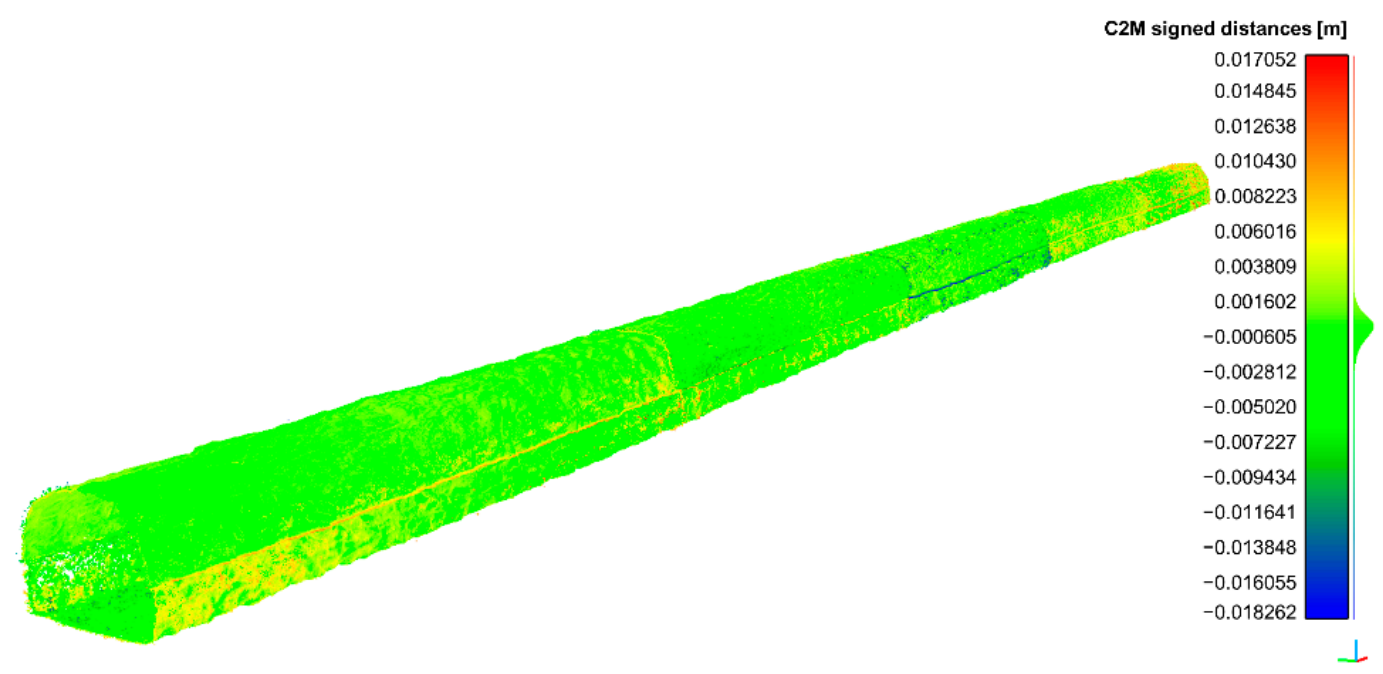

(b)

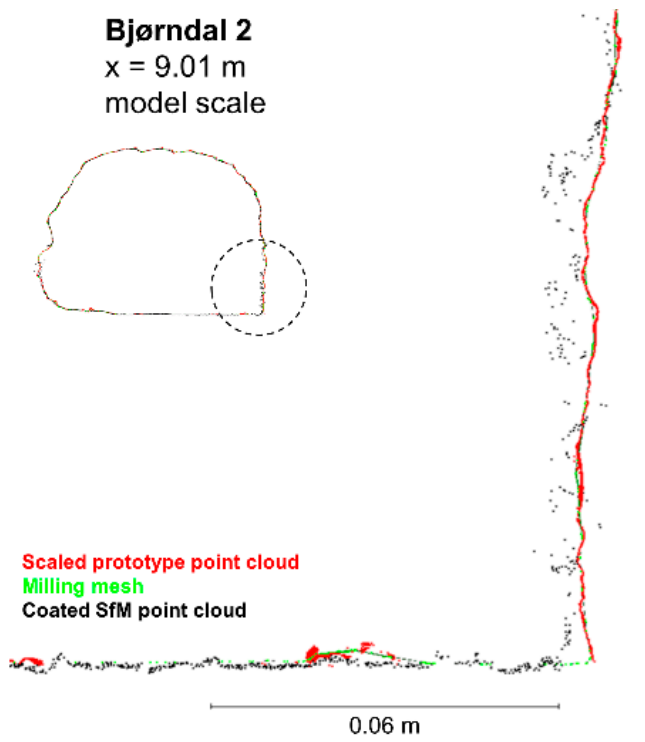

Figure 4. Difference plot between the milling mesh and the SfM point cloud of the coated Bjørndal 2 model (a) and a comparison of the scaled prototype point cloud (b), milling mesh and the coated SfM point cloud at a particular cross section $(x=9.01 \mathrm{~m})$. Note that the reduced point density of the scaled prototype point cloud at the tunnel invert is due to puddles of water on the invert during the scan. The water resulted in erroneous readings which had to be removed during post-processing of the data (see Section 2).

Deviations at the rough walls can be, besides the alignment of the mesh and SfM point cloud, attributed to the milling head size. This is further highlighted in Figure $4 \mathrm{~b}$ showing the direct comparison of the scaled prototype point cloud, the milling mesh and the coated SfM point cloud of the Bjørndal 2 model at a particular cross section $(\mathrm{x}=9.01 \mathrm{~m})$. The plot visualizes directly the smoothing effect at the $90^{\circ}$ angle of the tunnel at the lower right corner which could, however, be reproduced by the milling mesh. Similarly, larger deviations could typically be observed in troughs of larger roughness elements reflecting the limitations of the used milling head to reproduce such small cavities accurately. Moreover, further deviations could be observed along the vertical rough wall which may also be due to the surface coating. On the other hand, Figure $4 \mathrm{~b}$ shows that the rather smooth tunnel invert could be reproduced with high accuracy. Similar results were obtained for the two other tunnels for which the difference plots are provided in the Supplemental Material.

Overall, the obtained accuracy of the surface features was remarkable and, thus, it can be hypothesized that the identified differences between the scaled original point cloud 
and the coated model may not be significant for the subsequent hydraulic tests. A further issue that deserves attention in this context is the required spatial resolution of milled models. In the present case, the milling time was governed by the size of the ball nose cutter and the web spacing. The use of a finer milling head and web spacing would increase the production time and model costs considerably whereas the use of a coarser milling head and web spacing would result in a loss of accuracy. Presently, there is no guidance available regarding the required resolution of CNC-manufactured hydraulic scale models to adequately reproduce surface roughness features. This, in turn, calls for further research to optimize the costs and efficiency of such models.

Supplementary Materials: The following are available online at https://www.mdpi.com/article/10 .3390/w13070916/s1. Figure S1: Difference plot between the milling mesh and the coated SfM point cloud defining the digital twin of the Bjørndal 1 model. Note the different colour scale compared to Figures 4 and S2. Figure S2: Difference plot between the milling mesh and the coated SfM point cloud defining the digital twin of the Grøndal model. Note the different colour scale compared to Figures 4 and S1.

Author Contributions: Conceptualization, J.A. and P.-Y.H.; methodology, J.A., P.-Y.H., T.B., and R.E.; formal analysis, R.E. and T.B.; investigation, R.E., T.B., and J.A.; resources, J.A.; data curation, R.E. and T.B.; writing —original draft preparation, J.A. and R.E.; writing-review and editing, J.A., R.E., T.B., and P.-Y.H.; visualization, R.E. and T.B.; supervision, J.A., R.E., and T.B.; project administration, J.A.; funding acquisition, J.A. All authors have read and agreed to the published version of the manuscript.

Funding: This research was funded by the EnergiX-program of the Research Council of Norway (Norges Forskningsråd; project no. 255318/E20) in collaboration with the Norwegian Water Resources and Energy Directorate (NVE), the Norwegian Hydropower Centre (NVKS), and the industrial partners BKK and TrønderEnergi. This project is also affiliated with the research centre for environment-friendly energy research HydroCen.

Data Availability Statement: The data presented in this study are available on request from the corresponding author.

Acknowledgments: Anko carried out the TLS scans and provided the prototype point clouds. The authors also acknowledge the support of the DBFL-team and the staff at the LWI hydraulic laboratory for the production of the models. A special thanks is given to the contribution of Tatjana Hilmers and Katarina Strienz for their help with the accuracy evaluations for the Bjørndal 1 and Bjørndal 2 models. We acknowledge support by the German Research Foundation and the Open Access Publication Funds of Technische Universität Braunschweig.

Conflicts of Interest: The authors declare no conflict of interest. The funders had no role in the design of the study; in the collection, analyses, or interpretation of data; in the writing of the manuscript, or in the decision to publish the results.

\section{References}

1. Ettema, R. Role of hydraulic experiments. In Experimental Hydraulics, Volume I: Fundamentals and Methods; Section 1.2; Muste, M., Lyn, D.A., Admiraal, D.M., Ettema, R., Nikora, V., Garcia, M.H., Eds.; Taylor \& Francis Group: London, UK, 2017.

2. Hughes, S. Physical Models and Laboratory Techniques in Coastal Engineering; Advanced Series on Ocean Engineering; World Scientific Publishing: Singapore, 1993; Volume 7.

3. Novak, P.; Guinot, V.; Jeffrey, A.; Reeve, D.E. Hydraulic Modelling-An Introduction; Spon Press: London, UK; New York, NY, USA, 2010.

4. Muste, M.; Aberle, J.; Admiraal, D.; Ettema, R.; Garcia, M.; Lyn, D.; Nikora, V.; Rennie, C. (Eds.) Experimental Hydraulics: Methods, Instrumentation, Data Processing and Management; CRC Press: London, UK, 2017.

5. Rowiński, P.M. (Ed.) Experimental Methods in Hydraulic Research; GeoPlanet: Earth and Planetary Sciences; Springer: Heidelberg, Germany, 2011.

6. $\quad$ Baynes, E.R.C.; van de Lageweg, W.I.; McLelland, S.J.; Parsons, D.R.; Aberle, J.; Dijkstra, J.; Henry, P.-Y.; Rice, S.P.; Thom, M.; Moulin, F. Beyond equilibrium: Re-evaluating physical modelling of fluvial systems to represent climate changes. Earth-Sci. Rev. 2018, 181, 82-97. [CrossRef]

7. Addis, W. (Ed.) Physical Models: Their Historical and Current Use in Civil and Building Engineering Design; Ernst \& Sohn: Berlin, Germany, 2021. 
8. Henry, P.Y.; Aberle, J.; Anquetin, P.-G.; Grasso, F.; Bodewes, B.; Fernadez, R.L.; McLelland, S.; Vettori, D.; Caceres, I.; Marzeddu, A.; et al. Hydralab+ Deliverable D8.III Protocols for Scaling Morphodynamics in Time. Zenodo 2018. [CrossRef]

9. Heller, V. Scale effects in physical hydraulic engineering models. J. Hydraul. Res. 2011, 49, 293-306. [CrossRef]

10. Henry, P.-Y.; Aberle, J.; Navaratnam, C.U.; Rüther, N. Hydraulic physical model production with Computer Numerically Controlled (CNC) manufacturing techniques. In E3S Web of Conferences; EDP Sciences: Les Ulis, France, 2018; Volume 40, p. 05065. [CrossRef]

11. Webb, C.B.; Barfuss, S.L.; Johnson, M.C. Modelling roughness in scale models. J. Hydraul. Res. 2010, 48, 260-264. [CrossRef]

12. Chandler, J.H.; Buffin-Bélanger, T.; Rice, S.; Reid, I.; Graham, D.I. The accuracy of a river bed moulding/casting system and the effectiveness of a low-cost digital camera for recording river bed fabric. Photogramm. Rec. 2003, 18, 209-223. [CrossRef]

13. Buffin-Bélanger, T.; Reid, I.; Rice, S.; Chandler, J.H.; Lancaster, J. A casting procedure for reproducing coarse-grained sedimentary surfaces. Earth Surf. Process. Landf. 2003, 28, 787-796. [CrossRef]

14. Buffin-Bélanger, T.; Rice, S.; Reid, I.; Lancaster, J. Spatial heterogeneity of near-bed hydraulics above a patch of river gravel. Water Resour. Res. 2006, 42. [CrossRef]

15. Rice, S.P.; Buffin-Bélanger, T.; Reid, I. Sensitivity of interfacial hydraulics to the microtopographic roughness of water-lain gravels Earth Surf. Process. Landf. 2014, 39, 184-199. [CrossRef]

16. Spiller, S.; Rüther, N.; Friedrich, H. Dynamic lift on an artificial static armor layer during highly unsteady open channel flow. Water 2015, 7, 4951-4970. [CrossRef]

17. Cooper, J.R.; Ockleford, A.; Rice, S.P.; Powell, D.M. Does the permeability of gravel river beds affect near-bed hydrodynamics? Earth Surf. Process. Landf. 2018, 43, 943-955. [CrossRef]

18. Navaratnam, C.U.; Aberle, J.; Qin, J.; Henry, P.-Y. Influence of gravel-bed porosity and grain orientation on bulk flow resistance. Water 2018, 10, 561. [CrossRef]

19. Bertin, S.; Friedrich, H.; Delmas, P.; Chan, E.; Gimel'farb, G. Digital stereo photogrammetry for grain-scale monitoring of fluvial surfaces: Error evaluation and workflow optimisation. ISPRS J. Photogramm. Remote Sens. 2015, 101, 193-208. [CrossRef]

20. Brasington, J. Terrestrial Laser Scanning: Topographic measurement and modelling. In Experimental Hydraulics, Volume II: Instrumentation and Measurement Techniques; Section 4.2; Aberle, J., Rennie, C.D., Admiraal, D.M., Muste, M., Eds.; Taylor \& Francis: New York, NY, USA, 2017.

21. Henning, M.; Detert, M.; Aberle, J. Photogrammetry. In Experimental Hydraulics, Volume II: Instrumentation and Measurement Techniques; Section 4.4; Aberle, J., Rennie, C.D., Admiraal, D.M., Muste, M., Eds.; Taylor \& Francis: New York, NY, USA, 2017.

22. Stewart, M.T.; Cameron, S.M.; Nikora, V.I.; Zampiron, A.; Marusic, I. Hydraulic resistance in open-channel flows over self-affine rough beds. J. Hydraul. Res. 2019, 57, 183-196. [CrossRef]

23. Nikora, V.; Stoesser, T.; Cameron, S.; Stewart, M.; Papadopoulos, K.; Ouro, P.; McSherry, R.; Zampiron, A.; Marusic, I.; Falconer, R. Friction factor decomposition for rough-wall flows: Theoretical background and application to open-channel flows. J. Fluid Mech. 2019, 872, 626-664. [CrossRef]

24. Chua, C.K.; Leong, K.F. 3D Printing and Additive Manufacturing: Principles and Applications, 5th ed.; World Scientific Publishing Co. Pte. Ltd.: Singapore, 2017.

25. Liaw, C.-Y.; Guvendiren, M. Current and emerging applications of 3D printing in medicine. Biofabrication 2017, 9, 024102. [CrossRef] [PubMed]

26. Jia, Z.; Wang, L. 3D printing of biomimetic composites with improved fracture toughness. Acta Mater. 2019, 173, 61-73. [CrossRef]

27. Mohammed, J.S. Applications of 3D printing technologies in oceanography. Methods Oceanogr. 2016, 17, 97-117. [CrossRef]

28. Bhattacharjee, N.; Urrios, A.; Kang, S.; Folch, A. The upcoming 3D-printing revolution in microfluidics. Lab Chip 2016, 16, 1720-1742. [CrossRef]

29. Kloft, H.; Hack, N.; Lindemann, H.; Mainka, J. Shotcrete 3D printing (SC3DP)—3D-Drucken von großformatigen Betonbauteilen. Dtsch. Bauz. 2019, 2, 54-57.

30. Bertin, S.; Friedrich, H.; Delmas, P.; Chan, E.; Gimel'farb, G. DEM quality assessment with a 3d printed gravel bed applied to stereo photogrammetry. Photogramm. Rec. 2014, 29, 241-264. [CrossRef]

31. Hodge, R.A.; Hoey, T.B. A Froude-scaled model of a bedrock-alluvial channel reach: 1. Hydraulics. J. Geophys. Res. Earth Surf. 2016, 121, 1578-1596. [CrossRef]

32. Pedersen, Ø.; Aberle, J.; Rüther, N. Hydraulic scale modelling of the rating curve for a gauging station with challenging geometry. Hydrol. Res. 2019, 50, 825-836. [CrossRef]

33. Andersson, L.; Larsson, I.; Hellstrom, J.; Andreasson, P.; Andersson, A. Experimental Study of Head Loss over Laser scanned Rock Tunnel. In Hydraulic Structures and Water System Management, Proceedings of the 6th IAHR International Symposium on Hydraulic, Portland, OR, USA, 27-30 June 2016; Crookston, B.M., Tullis, B., Eds.; Utah State University: Logan, UT, USA, 2016 ; pp. 22-29. [CrossRef]

34. Aberle, J.; Henry, P.-Y.; Kleischmann, F.; Navaratnam, C.U.; Vold, M.; Eikenberg, R.; Olsen, N.R.B. Experimental and numerical determination of the head loss of a pressure driven flow through an unlined rock-blasted tunnel. Water 2020, 12, 3492. [CrossRef]

35. Aberle, J.; Branß, T.; Eikenberg, R.; Henry, P.-Y.; Olsen, N.R.B. Directional dependency of flow resistance in an unlined rock blasted hydropower tunnel. J. Hydraul. Res. 2021. under review. 
36. Mainka, J. Non-Waste-Wachsschalungen-Entwicklung Einer Wachsschalungstechnologie Für Geometrisch Komplexe Betonbauteile (Non-Waste-Wax-Formwork Technology). Ph.D. Thesis, Technische Universität Braunschweig, Braunschweig, Germany, 2019. [CrossRef]

37. CloudCompare. Available online: https://www.cloudcompare.org/doc/wiki/index.php?title=ICP (accessed on 10 February 2021).

38. Zang, Y.; Yang, B.; Li, J.; Guan, H. An Accurate TLS and UAV Image Point Clouds Registration Method for Deformation Detection of Chaotic Hillside Areas. Remote Sens. 2019, 11, 647. [CrossRef] 